Original Research Article

\title{
Evaluation of efficacy of palonosetron versus ramosetron in patients receiving emetogenic chemotherapy
}

\author{
Zainab Ghazala $^{1 *}$, Prakash Kalshetty ${ }^{1}$, Anuradha H. V. ${ }^{2}$
}

${ }^{1}$ Department of Pharmacology, KBNIMS, Kalaburagi,

Karnataka, India

${ }^{2}$ Department of Pharmacology, MS Ramaiah Medical College, Bangalore, Karnataka, India

Received: 07 January 2019

Accepted: 07 February 2019

\section{*Correspondence to: \\ Dr. Zainab Ghazala, \\ Email: \\ zainab.ghazala@gmail.com}

Copyright: (C) the author(s), publisher and licensee Medip Academy. This is an openaccess article distributed under the terms of the Creative Commons Attribution NonCommercial License, which permits unrestricted noncommercial use, distribution, and reproduction in any medium, provided the original work is properly cited.

\begin{abstract}
Background: Chemotherapy induced nausea and vomiting is the most distressing side effect of cancer chemotherapy. It can seriously impact patient's quality of life, influence the adherence to chemotherapy and progression free survival causing a delay or refusal of potentially life-saving therapy. The objective of this study was to compare the efficacy of palonosetron with ramosetron in achieving complete response to the chemotherapy.

Methods: This was a prospective randomized open-label study conducted on 130 patients admitted in Medical Oncology ward of a Tertiary Care Hospitals, Bangalore, India. Patients were randomized to receive either palonosetron 0.25 $\mathrm{mg}$ or ramosetron $0.3 \mathrm{mg}$ I.V. along with aprepitant and dexamethasone 30 minutes prior to chemotherapy and were followed up for a period of 5 days post chemotherapy. The observations such as number and severity of vomiting and nausea, the outcome was assessed at the end of 5 days. Pearson's Chi-square test was used to demonstrate the difference between both the study groups with respect to various categorical data.

Results: The complete response rate in delayed phase was more significant in patients who received palonosetron than patients who received ramosetron $(72.3 \%$ vs $50.8 \%)$. Total control was achieved in $38.5 \%$ patients with palonosetron as compared to $15.4 \%$ patients with ramosetron.

Conclusions: Palonosetron is more efficacious than ramosetron in controlling chemotherapy induced nausea and vomiting especially in delayed phase of emesis.
\end{abstract}

Keywords: Aprepitant, Chemotherapy induced nausea and vomiting, Dexamethasone, Moderately emetogenic chemotherapy, Palonosetron, Ramosetron

\section{INTRODUCTION}

Chemotherapy induced nausea and vomiting (CINV) are the most distressing side effects in cancer patients treated with chemotherapy and can have a negative impact on the patient's quality of life (QOL) as well as physical and cognitive functioning. ${ }^{1}$ CINV can seriously influence patient's adherence to chemotherapy and may thus influence progression free survival causing delay or refusal of potentially curative therapy. ${ }^{2-4}$ The individual patient risk of CINV is associated with the type of chemotherapy administered and specific patient characteristics. ${ }^{5,6}$ Despite advances in both cytotoxic agents and supportive care treatments, patients undergoing chemotherapy continue to suffer from nausea and vomiting. These complications can lead to serious medical problems, such as dehydration, electrolyte imbalance, increased duration of hospital stay and an associated rise in treatment costs, and impaired QOL for patients and their caregivers. Agents such as cisplatin and dacarbazine have high emetogenic potential with emesis in nearly all patients, while carboplatin, anthracyclines and cyclophosphamide are considered 
moderately emetogenic with emesis in $>70 \%$ of patients. Etoposide, gemcitabine and mitoxantrone are of low emetogenic potential with emesis in $10 \%$ to $70 \%$ of patients. Age $<50$ years, female gender, history of prior chronic low alcohol intake, history of motion sickness, and emesis during pregnancy are significant risk factors for CINV. The most clinically relevant antiemetic drugs are serotonin (5-Hydroxytryptamine) receptor antagonists (5HT3 RA), neurokinin-1 receptor antagonists (NK-1RA) like aprepitant and corticosteroids like dexamethasone and prednisolone. ${ }^{2}$ 5-HT3 RA class of drugs includes the firstgeneration agents (i.e., granisetron, ondansetron, tropisetron, dolasetron and ramosetron) and the novel second generation antagonist palonosetron. Comparison of palonosetron with ramosetron has been done for prophylaxis of post-operative nausea and vomiting after laproscopic cholecystectomy in which authors have concluded that palonosetron was better than ramosetron for long term prevention of post-operative nausea and vomiting (PONV). ${ }^{7}$ Individual studies have been done comparing various first generation 5HT3 antagonist with palonosetron alone and in combination with either dexamethasone or aprepitant for acute and delayed emesis. $^{8}$

Literature survey indicates the need for direct comparison of different combinations of the three drug regimens i.e. a 5HT3 antagonist with dexamethasone and aprepitant in moderate to highly emetogenic compounds to provide complete and long term protection against CINV. The objective of the study was to compare the efficacy of palonosetron and ramosetron in combination with aprepitant and dexamethasone in CINV in terms of complete response to MEC.

\section{METHODS}

The present study was conducted for a period of one year on the patients admitted to the Medical Oncology ward, Bangalore, India. The study was approved by the Institutional Ethics Committee. Informed consent was obtained from all the eligible subjects. The patients were assigned random numbers by permuting the number 130 in the random number table. The study was conducted as an open label randomized clinical trial.

Detailed medical history of the patients with respect to demographic details, general physical examination, vitals and systemic examination, existing co-morbidities that could manifest with nausea and vomiting and laboratory investigations were recorded in a pre-validated performa.

In study intervention, the two drugs palonosetron $0.25 \mathrm{mg}$ intravenously (IV) and ramosetron $0.3 \mathrm{mg}$ IV were given to the patients in group A (PAD regimen) and group B (RAD regimen) respectively, 30 minutes before chemotherapy. Both the groups received aprepitant 125 mg per oral (p.o) on day 1 and $80 \mathrm{mg}$ p.o on day 2 and day 3 before chemotherapy. Both the groups also received dexamethasone $8 \mathrm{mg}$ I.V. $30 \mathrm{~min}$ before chemotherapy on day 1 and $4 \mathrm{mg}$ BD p.o from day 2-4. In follow up, patients were provided diaries to document the number of emetic episodes, breakthrough nausea medications, and severity of nausea during the 120-hour observation period after the infusion of chemotherapy. After discharge from the hospital patients were followed up by telephonic interview. Any adverse events reported by the patients during the follow up period of 120 hours were also documented.

\section{Inclusion criteria}

Males and females aged 18 to 75 years with Eastern Cooperative Oncology Group (ECOG) performance status 0-2 (Table 1) and histologically proven solid cancer. These patients were to be chemotherapy naive and planned to receive moderately emetogenic chemotherapy.

\section{Table 1: ECOG performance status.}

\begin{tabular}{|ll|}
\hline Grade & Features \\
\hline 0 & $\begin{array}{l}\text { Fully active, able to carry out all pre-disease } \\
\text { performance without restriction. }\end{array}$ \\
\hline 1 & $\begin{array}{l}\text { Restricted in physically strenuous activity } \\
\text { but ambulatory and able to carry out work of } \\
\text { light or sedentary nature. } \\
\text { Ex: light house work, office work. }\end{array}$ \\
\hline 2 & $\begin{array}{l}\text { Ambulatory and capable of all self-care but } \\
\text { unable to carry out any work activities. Up } \\
\text { and about more than 50\% of waking hours. }\end{array}$ \\
\hline 3 & $\begin{array}{l}\text { Capable of only limited self-care, confined } \\
\text { to bed or chair more than 50\% of waking } \\
\text { hours. }\end{array}$ \\
\hline 4 & $\begin{array}{l}\text { Completely disabled. Cannot carry out any } \\
\text { self-care activities. Totally confined to bed } \\
\text { or chair. }\end{array}$ \\
\hline 5 & Dead. \\
\hline
\end{tabular}

ECOG: Eastern Co-Operative Oncology Group.

\section{Exclusion criteria}

Patients with active infection, severe heart disease (NYHA grade III and IV), uncontrolled hypertension or diabetes mellitus (HbA1c >10), active gastric or duodenal ulcers. Pregnant and lactating females, patients with symptomatic primary or secondary brain neoplasm were excluded from the study.

\section{Sample size calculation}

Study done by Grote T et al, which was a phase II clinical trial with a sample size of 58 showed that prophylaxis with PAD regimen resulted in a complete response in $88 \%$ patients in acute phase and $78 \%$ in delayed phase after giving MEC. ${ }^{9}$ For the present study, a sample size of 130 was estimated to detect at least $20 \%$ difference in CR rate between both the groups at $5 \%$ significance level and $80 \%$ power. The sample size calculation was done using $\mathrm{n}$ Master software. 


\section{Efficacy parameter}

\section{Complete response rate}

Proportion of patients with emesis in the acute (day 1) and delayed (days 2-5) phases after chemotherapy in both the study groups. A single emetic episode was defined as emesis separated by less than a 5-minute interval.

\section{The outcome was assessed in terms of symptom control}

Total control defined as no nausea, no vomiting, no retching and no rescue medications, good control defined as 1-3 episodes of vomiting in 24 hours may or may not be accompanied with nausea, and antiemetic failure defined as more than 3 episodes of vomiting in 24 hours.

\section{RESULTS}

Figure 1 shows the randomization scheme of the participants included in the study.

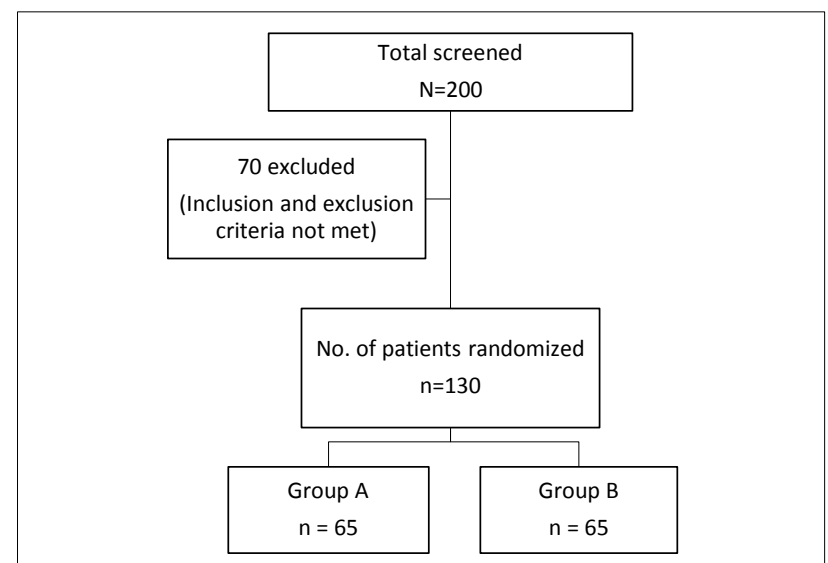

Figure 1: Randomization chart.

Both the study groups were age matched with $\mathrm{P}=0.442$. The gender distribution was comparable in both the study groups with $\mathrm{P}=0.149$. The ECOG status of the patients was comparable in both the study groups with $\mathrm{P}=0.392$. The distribution of various diagnoses was comparable between both the study groups with $\mathrm{p}=0.711$.

Table 2: Complete response rate (delayed phase) in both the study groups.

\begin{tabular}{|ll|}
\hline Treatment regimen & CR $\mathbf{n}(\%)$ \\
\hline PAD $(\mathrm{n}=65)$ & $47(72.3)$ \\
\hline RAD $(\mathrm{n}=65)$ & $33(50.8)$ \\
\hline
\end{tabular}

$\mathrm{CR}=$ complete response.

Table 2 shows efficacy parameter in terms of complete response rate which was seen to be significantly more in $\mathrm{PAD}$ regimen group than $\mathrm{RAD}$ regimen with $\mathrm{P}=0.012$ $(\mathrm{OR}=2.5 ; 95 \% \quad \mathrm{CI}=1.22-5.25)$. Table 3 shows the difference between the outcome of chemotherapy with both the antiemetic regimens as statistically significant with $\mathrm{P}=0.01$.

Table 3: Comparison of outcome in both the study groups.

\begin{tabular}{|llll|}
\hline $\begin{array}{l}\text { Treatment } \\
\text { regimen }\end{array}$ & $\begin{array}{l}\text { Outcome }(\%) \\
\text { Total } \\
\text { control }\end{array}$ & $\begin{array}{l}\text { Good } \\
\text { control }\end{array}$ & $\begin{array}{l}\text { Antiemetic } \\
\text { failure }\end{array}$ \\
\hline PAD $(n=65)$ & 38.5 & 49.2 & 12.3 \\
\hline RAD $(n=65)$ & 15.4 & 72.3 & 12.3 \\
\hline Total $(n=130)$ & 26.9 & 60.8 & 12.3 \\
\hline
\end{tabular}

\section{DISCUSSION}

The present study was conducted to study the efficacy of two regimens i.e. palonosetron along with aprepitant and dexamethasone (PAD) vs ramosetron along with aprepitant and dexamethasone (RAD) in obtaining a complete response after the first cycle of a moderately emetogenic chemotherapy. This study was the first of its kind to compare the two newer regimes in controlling CINV especially in the delayed phase of emesis. Analysis of the baseline data showed that both the study groups were comparable with respect to age, gender, ECOG performance status.

The complete response rate (defined as no nausea and vomiting, no rescue medications) in early phase (first 24 hours) was similar in both the study groups where as in the delayed phase (25-120 hours) it was $72.3 \%$ and $50.8 \%$ with PAD and RAD regimen respectively with OR of 2.5 and 95\% CI between 1.22-5.25. The difference was statistically significant in the delayed phase with $\mathrm{p}=0.012$ as shown in Table 2 .

The outcome was also assessed in terms of symptom control. Total control (defined as no nausea, no vomiting, no retching, no rescue medication up to 120 hours) was seen in $38.5 \%$ patients in PAD regimen and $15.4 \%$ patients in RAD regimen group while good control (defined as 1-3 episodes of vomiting in 24 hours) was achieved in $49.2 \%$ and $72.3 \%$ patients with PAD and RAD regimens respectively as shown in Table 3 .

The difference for these two parameters was statistically significant $(\mathrm{p}=0.01)$. There was no difference between both the study groups with respect to antiemetic failure. A study done by Saito $\mathrm{M}$ et al, indicated that the $2^{\text {nd }}$ generation $5 \mathrm{HT}_{3} \mathrm{RA}$ had extended efficacy in controlling delayed CINV. ${ }^{10}$ Grote $\mathrm{T}$ et al, in their study had observed a complete response of $88 \%$ in early phase and $78 \%$ in delayed phase in patients receiving the three drug regimen comprising palonosetron, aprepitant and dexamethasone. ${ }^{9}$ Similar observations were made in the present study. While there was no difference between both the study groups in complete response rate in early phase, it was significantly more with PAD regimen in the delayed phase $(72.3 \%$ vs $50 \%)$. 


\section{Strengths of the study}

It was a randomized controlled trial. It was the first study to compare two newer regimes (PAD and RAD) for the control of CINV. The present study included patients of various solid cancers and in wide age limit. Hence, the results can be extrapolated to a larger population receiving cancer chemotherapy.

\section{Limitations of the study}

The study was not blinded. A subgroup analysis with respect to response of the patients to different chemotherapeutic agents could not be made separately as all the chemotherapeutic agents were broadly classified as minimal, low, moderately or highly emetogenic at the time of patient inclusion.

Long term safety of the study drugs could not be assessed as the patients were followed up only for 120 hours post chemotherapy.

\section{CONCLUSION}

The present study was conducted mainly to assess the efficacy of two commonly used drugs palonosetron and ramosetron along with aprepitant and dexamethasone which have proven benefit in controlling nausea and vomiting post chemotherapy. In the present study, it was observed that patients who received a single dose of palonosetron $0.25 \mathrm{mg}$ I.V. along with aprepitant and dexamethasone had better control of vomiting than those who received ramosetron ( $72 \%$ vs $50 \%)$ especially in delayed phase of emesis. However, there was no difference among the two study groups in early phase of emesis. This observation can be clearly attributed to the mechanism of action of palonosetron as described in the review of literature. The patients who received PAD regimen for the prophylaxis of emesis had better outcome in terms of symptom control at end of follow-up period post chemotherapy. Thus, the results clearly indicated that palonosetron was more efficacious than ramosetron in controlling nausea and vomiting especially in the delayed phase in patients receiving MEC.

Funding: No funding sources Conflict of interest: None declared

Ethical approval: The study was approved by the Institutional Ethics Committee

\section{REFERENCES}

1. Ballatori E, Roila F, Ruggeri B, Betti M, Sarti S, Soru $\mathrm{G}$, et al. The impact of chemotherapy-induced nausea and vomiting on health-related quality of life. Supportive Care Cancer. 2007;15(2):179-85.

2. Cohen L, Moor CA, Eisenberg P, Ming EE, Hu H. Chemotherapy-induced nausea and vomiting- incidence and impact on patient quality of life at community oncology settings. Supportive Care Cancer. 2007;15(5):497-503.

3. Hickok JT, Roscoe JA, Morrow GR, King DK, Atkins JN, Fitch TR. Nausea and emesis remain significant problems of chemotherapy despite prophylaxis with 5hydroxytryptamine-3 antiemetics. Cancer. 2003;97(11):2880-6.

4. Grunberg SM, Deuson RR, Mavros P, Geling O, Hansen M, Cruciani G, et al. Incidence of chemotherapy-induced nausea and emesis after modern antiemetics: perception versus reality. Cancer: Interdisciplinary Inter $\mathrm{J}$ Am Cancer Soc. 2004;100(10):2261-668.

5. Grunberg SM, Osoba D, Hesketh PJ, Gralla RJ, Borjeson S, Rapoport BL, et al. Evaluation of new antiemetic agents and definition of antineoplastic agent emetogenicity-an update. Supportive Care Cancer. 2005;13(2):80-4.

6. Navari RM, Province PS. Emerging drugs for chemotherapy-induced emesis. Expert Opinion Emerging Drugs. 2006;11(1):137-51.

7. Gautam Piplai, Indrani Chakrabarty DA, Madhumita Mukhopadhyay MS, Manas Karmakar, Sabyasachi Sarkar MS, et al. A comparative study between palonosetron and ramosetron to prevent postoperative nausea and vomiting after laparoscopic cholecystectomy. Inter Res J Pharmacy Pharmacol. 2012;2(8):193-7.

8. Rubenstein EB, Gralla RJ, Eisenberg P. Palonosetron (PALO) compared with ondansetron (OND) or dolasetron (DOL) for prevention of acute and delayed chemotherapy-induced nausea and vomiting (CINV): combined results of two-phase III trials. Proc Am Soc Clin Oncol. 2003;22:729.

9. Grote T, Hajdenberg J, Cartmell A, Ferguson S, Ginkel A, Charu V. Combination therapy for chemotherapy-induced nausea and vomiting in patients receiving moderately emetogenic chemotherapy: palonosetron, dexamethasone, and aprepitant. J Supportive Oncol. 2006;4(8):403-8.

10. Saito M, Aogi K, Sekine I, Yoshizawa H, Yanagita Y, Sakai H, et al. Palonosetron plus dexamethasone versus granisetron plus dexamethasone for prevention of nausea and vomiting during chemotherapy: a double-blind, double-dummy, randomised, comparative phase III trial. Lancet Oncol. 2009;10(2):115-24.

Cite this article as: Ghazala Z, Kalshetty $P$, Anuradha HV. Evaluation of efficacy of palonosetron versus ramosetron in patients receiving emetogenic chemotherapy. Int J Basic Clin Pharmacol 2019;8:681-4. 